\title{
New Alkaloids From a Hawaiian Fungal Strain Aspergillus felis FM324
}

\author{
Cong Wang ${ }^{1,2}$, Ariel M. Sarotti ${ }^{3}$, KH Ahammad Uz Zaman ${ }^{1}$, Xiaohua $W^{1}{ }^{1}$ and Shugeng Cao ${ }^{1 *}$ \\ ${ }^{1}$ Department of Pharmaceutical Sciences, Daniel K. Inouye College of Pharmacy, University of Hawai'i at Hilo, Hilo, HI, \\ United States, ${ }^{2}$ Key Laboratory of Chemistry and Engineering of Forest Products, State Ethnic Affairs Commission, Guangxi Key \\ Laboratory of Chemistry and Engineering of Forest Products, Guangxi Collaborative Innovation Center for Chemistry and \\ Engineering of Forest Products, School of Chemistry and Chemical Engineering, Guangxi University for Nationalities, Nanning, \\ China, ${ }^{3}$ Facultad de Ciencias Bioquímicas y Farmacéuticas, Instituto de Química Rosario (CONICET), Universidad Nacional de \\ Rosario, Rosario, Argentina
}

Two new alkaloids tryptoquivaline $Y$ (1) and pseurotin I (2), together with eight known compounds (3-10), were purified from a fungal strain Aspergillus felis FM324, which was isolated from a Hawaiian beach soil sample. The absolute configuration and physicochemical data of tryptoquivaline $Z$ (3) were reported for the first time here in this paper. Compound 1 is an uncommon tryptoquivaline analog containing a 3-Oisobutanoyl group. The structures of the new compounds 1-2 and known compound 3 were elucidated through HRESIMS, NMR spectroscopy and ECD analysis. All the compounds were evaluated for their antiproliferative, antibacterial and NF-kB inhibitory activities. Compound 4 showed weak antibacterial activity against Staphylococcus aureus, methicillin resistant Staphylococcus aureus and Bacillus subtilis with the same MIC value of $59.2 \mu \mathrm{M}$. Compounds $\mathbf{3}$ and $\mathbf{2}$ inhibited NF- $\mathrm{kB}$ with $\mathrm{IC}_{50}$ values of 26.7 and $30.9 \mu \mathrm{M}$, respectively.

Keywords: Aspergillus felis, trichocomaceae, alkaloids, antiproliferative, antibacterial, NF-kB inhibitory activities

\section{INTRODUCTION}

Marine fungi remain one of the few underexplored resources of natural products (Overy et al., 2019), and they have become the main source of new compounds from marine microorganisms due to their complex genetic background (Zhao et al., 2016). Most of the reported marine fungal secondary metabolites showed certain biological properties including antibacterial (Wang et al., 2021) and anticancer (Deshmukh et al., 2017) activities. Aspergillus is a huge and diverse fungal genus (Ibrahim and Asfour, 2018), ubiquitously found in soil, terrestrial plants, animals and marine. Totally, there are about 380 species in the genus Aspergillus. As a dominant and the most studied fungal genus in endophytes, more than 350 new fungal metabolites were isolated from Aspergillus during 2015-2019 (Vadlapudi et al., 2017). Marine Aspergillus sp. produced plenty of secondary metabolites including polyketides, sterols, fatty acids, peptides, alkaloids, terpenoids and miscellaneous compounds, which exhibited different pharmacological activities such as antimicrobial, cytotoxicity, anti-inflammatory and antioxidant activity (Ibrahim et al., 2017a; Ibrahim et al., 2017b; Elkhayat, et al., 2016; Mohamed, et al., 2020). In the past few years, our research group has studied the secondary metabolites of some marine fungi including different Aspergillus species from Hawaii. These secondary metabolites had different types of structures and exhibited various biological activities (Li et al., 2015; Fei-Zhang et al., 2016; Li et al., 2016; Huang et al., 2017; Li et al., 2018; Li et al., 2019; Wang et al., 2019; Zaman et al., 2020a; Wang et al., 2020; Zaman et al., 2021). In our continuing search for bioactive molecules from Hawaiian fungi, we studied an extract of Aspergillus felis FM324, which led to the separation and 
identification of ten compounds (1-10). Here, we report two new molecules (1-2) along with eight known secondary metabolites (3-10). Compounds 1-10 were evaluated for their NF- $\mathrm{B}$ inhibitory property and anti-proliferative activity against A2780 as well as their antibacterial potential against both Gram-positive and Gram-negative bacteria.

\section{MATERIALS AND METHODS}

\section{General Experimental Procedures}

Optical rotations, CD, UV and FT-IR spectra were measured with a Rudolph Research analytical AutoPol automatic polarimeter (Rudolph Research Analytical, NJ, United States), JASCO J-815 CD (Jasco Corporation, Japan), Shimadzu UV spectrophotometer UV-1800 and Thermo Scientific Nicolet iS10 IR spectrometer (Thermo Fisher Scientific, WI, United States), respectively. The structure characterizations of all the compounds were based on $1 \mathrm{D} \operatorname{NMR}\left({ }^{1} \mathrm{H},{ }^{13} \mathrm{C}\right)$ and $2 \mathrm{D}$ NMR (COSY, HSQC, HMBC, 1D-NOE and ROESY) data, recorded on a Bruker AM-400 spectrometer (Bruker BioSpin AG, Switzerland). An Agilent 6,530 Accurate-Mass Q-TOF LCMS spectrometer (Agilent Technologies, Germany) was used to record high-resolution mass spectra. Preparative RP-HPLC was carried out on an Ultimate 3000 chromatographic system (Agilent Technologies, Germany) with a Phenomenex preparative column (Phenyl-hexyl, $5 \mu, 100 \times 21.2 \mathrm{~mm}$ ) and semipreparative RP-HPLC on an Ultimate 3000 chromatographic system (Agilent Technologies, Germany) with a Phenomenex semipreparative column $\left(C_{18}, 5 \mu, 250 \times\right.$ $10 \mathrm{~mm})$, connected to a Dionex Ultimate 3000 DAD detector (Agilent Technologies, Germany) (detected at 210, 254, 320, and $365 \mathrm{~nm}$ ) and a Dionex Ultimate 3000 automated fraction collector. All solvents were HPLC grade. Diaion HP-20 (Alfa Aesar, Japan) was used to run the open-column chromatography.

\section{Strain Isolation and Fermentation}

The strain FM324 was isolated from a sample collected at a beach at Kona, the Big Island, Hawaii. The strain was deposited in an $-80^{\circ} \mathrm{C}$ freezer at Daniel $\mathrm{K}$. Inouye College of Pharmacy, University of Hawaii at Hilo, HI, United States. The strain was grown on PDA plates at $28^{\circ} \mathrm{C}$ for 3 days, then it was cut into small pieces and inoculated into an autoclaved liquid $\mathrm{PDB}$ medium (20 L) for fermentation at $24^{\circ} \mathrm{C}$ for 30 days.

\section{Molecular Identification of the Fungal Strain M324}

DNA extraction: DNA was extracted according to the literature (Liu et al., 2000), with slight modifications. Mycelium was added to $500 \mu \mathrm{l}$ of lysis buffer $(400 \mathrm{mM}$ Tris- $\mathrm{HCl}$ [pH 8.0], $60 \mathrm{mM}$ EDTA, $150 \mathrm{mM} \mathrm{NaCl}, 1 \%$ sodium dodecyl sulfate) and incubated at $85^{\circ} \mathrm{C}$ for $20 \mathrm{~min}$. After adding $150 \mu \mathrm{l}$ of $3 \mathrm{M}$ sodium acetate $(\mathrm{pH}$ $5.2)$, the tube was vortexed briefly and centrifuged (12,500rpm) for $1 \mathrm{~min}$. The supernatant was transferred to another tube and centrifuged again. After transferring the supernatant to a new tube, an equal volume of isopropanol was added and mixed by inversion. The tube was centrifuged for $2 \mathrm{~min}$ and the supernatant was discarded. The DNA pellet was washed twice with $300 \mu \mathrm{l}$ of $70 \%$ ethanol. The DNA was air dried at room temperature for $45 \mathrm{~min}$, then dissolved in $100 \mu \mathrm{L}$ of $10 \mathrm{mM}$ Tris$\mathrm{HCl}$ ( $\mathrm{pH}$ 8.0). Sequencing of ITS region: The ITS region was amplified with the ITS1 and ITS4 primers. The PCR reaction included 1X High Fidelity PCR Buffer (Invitrogen), $2 \mathrm{mM}$ MgSO4, $0.2 \mathrm{mM}$ dNTP mix, 4\% DMSO, $0.2 \mu \mathrm{M}$ of each primer, $1 \mathrm{U}$ Platinum Taq DNA Polymerase High Fidelity (Invitrogen), and $10 \mathrm{ng}$ of genomic DNA. The PCR cycling conditions were $95^{\circ} \mathrm{C}$ for $3 \mathrm{~min}$, followed by 35 cycles of $95^{\circ} \mathrm{C}$ for $30 \mathrm{~s}, 50^{\circ} \mathrm{C}$ for $30 \mathrm{~s}$ and $72^{\circ} \mathrm{C}$ for $1 \mathrm{~min}$, and a final extension of $72^{\circ} \mathrm{C}$ for $5 \mathrm{~min}$. The PCR product was purified using Mag-Bind Total Pure NGS beads (Omega Bio-tek), then sequenced using a 3730xl DNA Analyzer (Applied Biosystems). The sequence was compared to the NCBI nucleotide collection (limited to sequences from type material) using the Basic Local Alignment Search Tool (BLAST), and was deposited in GenBank under the accession no. MZ227547.

\section{Extraction and Isolation}

After filtration of the fermentation broth, the mycelia of FM324 were extracted three times with acetone. Acetone was removed by evaporation in vacuum. After combining the aqueous mycelia extraction and supernatant solution, it was subjected to HP-20 column eluted with $\mathrm{MeOH}-\mathrm{H}_{2} \mathrm{O}$ into four fractions $(30,50,90$ and $100 \% \mathrm{MeOH})$. Fraction 3 (3.21 g) was separated by using prep-HPLC (Phenyl-Hexyl, $100 \times 21.20 \mathrm{~mm}, 5 \mu \mathrm{m} ; 8 \mathrm{ml} / \mathrm{min}$ ) eluted with $40-100 \% \mathrm{MeOH}-\mathrm{H}_{2} \mathrm{O}$ in $20 \mathrm{~min}$ to yield 26 subfractions (SFr3-1 26). SFr 3-11 (180 mg) was purified by semipreparative $\mathrm{HPLC}\left(38 \% \mathrm{MeCN} / \mathrm{H}_{2} \mathrm{O}, \mathrm{v} / \mathrm{v}, 1.0 \%\right.$ formic acid, $3.0 \mathrm{ml} / \mathrm{min}$ ) over a $\mathrm{C} 18$ column to afford compound 1 (1.6 $\left.\mathrm{mg}, t_{\mathrm{R}} 32.2 \mathrm{~min}\right)$. SFr 3-14 (152.7 mg) was purified by semipreparative HPLC $\left(20 \% \mathrm{MeCN} / \mathrm{H}_{2} \mathrm{O}, \mathrm{v} / \mathrm{v}, 1.0 \%\right.$ formic acid, $3.0 \mathrm{ml} / \mathrm{min}$ ) over a $\mathrm{C} 18$ column to afford compounds 2 (1.2 $\left.\mathrm{mg}, t_{\mathrm{R}} 35.3 \mathrm{~min}\right)$ and $7\left(2.2 \mathrm{mg}, t_{\mathrm{R}} 21.4 \mathrm{~min}\right)$. SFr 3-9 (720 mg) was purified by semi-preparative $\mathrm{HP} 2 \mathrm{LC}\left(30 \% \mathrm{MeCN} / \mathrm{H}_{2} \mathrm{O}\right.$, v/v, $1.0 \%$ formic acid, $3.0 \mathrm{ml} / \mathrm{min}$ ) over a $\mathrm{C} 18$ column to afford compounds 3 ( $\left.2.7 \mathrm{mg}, t_{\mathrm{R}} 27.6 \mathrm{~min}\right)$ and $5\left(1.6 \mathrm{mg}, t_{\mathrm{R}} 8.3 \mathrm{~min}\right)$. SFr 3-20 (100.1 mg) was purified by semi-preparative HPLC $\left(60 \% \mathrm{MeCN} / \mathrm{H}_{2} \mathrm{O}, \mathrm{v} / \mathrm{v}, 1.0 \%\right.$ formic acid, $\left.3.0 \mathrm{ml} / \mathrm{min}\right)$ over a $\mathrm{C} 18$ column to afford compound 4 (1.1 mg, $\left.t_{\mathrm{R}} 16.5 \mathrm{~min}\right)$. SFr 3-17 $(6.3 \mathrm{mg})$ afford compound 6 (6.3 mg). SFr 3-12 (201.8 mg) was purified by semi-preparative HPLC $\left(30 \% \mathrm{MeCN} / \mathrm{H}_{2} \mathrm{O}\right.$, v/v, $1.0 \%$ formic acid, $3.0 \mathrm{ml} / \mathrm{min}$ ) over a C18 column to afford compounds $8\left(12.6 \mathrm{mg}, t_{\mathrm{R}} 19.8 \mathrm{~min}\right), \mathbf{9}\left(5.2 \mathrm{mg}, t_{\mathrm{R}} 23.9 \mathrm{~min}\right)$ and $10(1.0 \mathrm{mg}$, $\left.t_{\mathrm{R}} 26.3 \mathrm{~min}\right)$.

Tryptoquivaline Y (1): White amorphous powder; $[\alpha]_{D}^{25}+135$ (c 0.10, MeOH); UV (MeOH) $\lambda_{\max }(\log \varepsilon) 212$ (4.42), 302 (3.47) $\mathrm{nm} ; \mathrm{CD}(0.10 \mathrm{mM}, \mathrm{MeOH}) \lambda_{\max }(\Delta \varepsilon) 224$ (-29.85), $250(+21.67)$, $288(+16.88) \mathrm{nm}$; IR (KBr) $\nu_{\max } 3,335,2,921,2,847,1,651,1,613$, $1,519,1,418,1,375,1,344,1,271,1,235,1,083,1,050,1,033$, $748.4 \mathrm{~cm}^{-1}$; ${ }^{1} \mathrm{H}$ and ${ }^{13} \mathrm{C}$ NMR data (see Table 1); HRESIMS $m / z 521.2042[\mathrm{M}+\mathrm{H}]^{+}$(calcd for $\mathrm{C}_{27} \mathrm{H}_{29} \mathrm{~N}_{4} \mathrm{O}_{7}, 521.2031$ ).

Pseurotin I (2): White amorphous powder; $[\alpha]_{D}^{25}-5.6(c 0.50$, $\mathrm{MeOH}) ; \mathrm{UV}(\mathrm{MeOH}) \lambda_{\max }(\log \varepsilon) 204$ (4.03), 252 (3.81), 280 (3.57) nm; CD (0.11 mM, MeOH) $\lambda_{\max }(\Delta \varepsilon) 210(+18.00), 232$ 
TABLE 1 | ${ }^{1} \mathrm{H}(400 \mathrm{MHz})$ and ${ }^{13} \mathrm{C}(100 \mathrm{MHz})$ NMR data of compounds $1-3$ in DMSO- $d_{6}$.

\begin{tabular}{|c|c|c|c|c|c|c|}
\hline \multirow[t]{2}{*}{ No } & \multicolumn{2}{|c|}{1} & \multicolumn{2}{|r|}{2} & \multicolumn{2}{|c|}{3} \\
\hline & $\delta_{\mathrm{C}}$ & $\delta_{\mathrm{H}}(J$ in $\mathrm{Hz})$ & $\delta_{\mathrm{C}}$ & $\delta_{\mathrm{H}}(\mathrm{J}$ in $\mathrm{Hz})$ & $\delta_{\mathrm{C}}$ & $\delta_{\mathrm{H}}(J$ in $\mathrm{Hz})$ \\
\hline 2 & $85.1, \mathrm{CH}$ & $5.08(s)$ & 187.0, C & - & $84.7, \mathrm{CH}$ & $4.88(s)$ \\
\hline 3 & $84.1, \mathrm{C}$ & - & 111.6, C & - & 77.3, C & \\
\hline 4 & $139.8, \mathrm{C}$ & - & 196.8, C & - & 138.2, C & \\
\hline 5 & $123.8, \mathrm{CH}$ & $7.36(\mathrm{~d}, 6.5)$ & $92.5, \mathrm{C}$ & - & $124.8, \mathrm{CH}$ & $7.38(\mathrm{~d}, 7.8)$ \\
\hline 6 & 124.7, $\mathrm{CH}$ & 7.09 (m) & 166.6, C & - & 124.7, $\mathrm{CH}$ & $7.11(\mathrm{dd}, 7.8,6.6)$ \\
\hline 7 & 130.0, CH & 7.35 (overlap) & - & - & 129.5, CH & $7.11(\mathrm{dd}, 7.8,6.6)$ \\
\hline 7-NH & - & - & - & 9.95 (s) & - & - \\
\hline 8 & 114.9, $\mathrm{CH}$ & 7.35 (overlap) & $91.2, \mathrm{C}$ & - & 114.7, $\mathrm{CH}$ & $7.42(\mathrm{~d}, 7.8)$ \\
\hline 9 & 133.6, C & - & $75.0, \mathrm{CH}$ & 4.40 (brs) & 137.1, C & - \\
\hline 10 & $170.1, \mathrm{C}$ & & $71.9, \mathrm{CH}$ & $4.33(\mathrm{~d}, 5.8)$ & $170.7, \mathrm{C}$ & - \\
\hline 11 & $58.0, \mathrm{CH}$ & 5.29 (brs) & $68.3, \mathrm{CH}$ & $4.45(d d d, 5.8,7.8,11.0)$ & $58.6, \mathrm{CH}$ & 5.22 (brs) \\
\hline 12 & $38.2, \mathrm{CH}_{2}$ & $\begin{array}{l}2.81(d, 14.4) \\
3.15(d d, 14.4,7.7)\end{array}$ & $129.9, \mathrm{CH}$ & 5.42 (overlap) & 38.0, $\mathrm{CH}_{2}$ & $\begin{array}{l}2.74(d, 15.6) \\
2.81(d d, 15.6,7.0)\end{array}$ \\
\hline 13 & 173.1, C & - & 132.0, $\mathrm{CH}$ & 5.44 (overlap) & 172.3, C & - \\
\hline 14 & $69.4, \mathrm{C}$ & - & 29.3, $\mathrm{CH}_{2}$ & $2.02(\mathrm{~m}) ; 1.97(\mathrm{~m})$ & 69.6, C & - \\
\hline 15 & & - & $22.2, \mathrm{CH}_{2}$ & $1.31(\mathrm{~m}) ; 1.28(\mathrm{~m})$ & - & - \\
\hline 16 & & - & 13.6, $\mathrm{CH}_{3}$ & $0.82(t, 7.3)$ & - & - \\
\hline 17 & $160.2, \mathrm{C}$ & - & $5.7, \mathrm{CH}_{3}$ & 1.63 (s) & 159.9, C & - \\
\hline 18 & 121.6, C & - & $196.4, \mathrm{C}$ & - & $121.8, \mathrm{C}$ & - \\
\hline 19 & 126.1, CH & $8.19(\mathrm{~d}, 7.0)$ & $133.4, \mathrm{C}$ & - & 126.1, CH & $8.18(d, 8.0)$ \\
\hline 20 & 127.1, $\mathrm{CH}$ & $7.59(t, 7.0)$ & 130.3, CH & 8.25 (overlap) & 127.0, $\mathrm{CH}$ & $7.59(t, 8.0,7.3)$ \\
\hline 21 & 134.6, CH & $7.88(t, 8.0)$ & $128.4, \mathrm{CH}$ & $7.53(t, 8.0)$ & $134.5, \mathrm{CH}$ & $7.87(\mathrm{~d}, 8.2,7.3)$ \\
\hline 22 & 127.1, CH & $7.75(\mathrm{~d}, 8.0)$ & 133.9, CH & $7.67(\mathrm{t}, 7.4)$ & $127.1, \mathrm{CH}$ & $7.73(\mathrm{~d}, 8.2)$ \\
\hline 23 & $147.8, \mathrm{C}$ & - & $128.4, \mathrm{CH}$ & $7.53(\mathrm{t}, 8.0)$ & $147.9, \mathrm{C}$ & - \\
\hline 24 & - & - & 130.3, CH & 8.25 (overlap) & - & - \\
\hline 25 & 148.6, CH & 8.57 (s) & - & - & 149.2, CH & 8.52 (s) \\
\hline 26 & 18.2, $\mathrm{CH}_{3}$ & 1.34 (s) & - & - & $16.5, \mathrm{CH}_{3}$ & 1.30 (s) \\
\hline 27 & $22.5, \mathrm{CH}_{3}$ & $1.13(\mathrm{~s})$ & - & - & 22.7, $\mathrm{CH}_{3}$ & $1.28(\mathrm{~s})$ \\
\hline 28 & 174.0, C & - & - & - & - & - \\
\hline 29 & $33.0, \mathrm{CH}$ & $2.16(\mathrm{~s})$ & - & - & - & - \\
\hline 30 & $18.1, \mathrm{CH}_{3}$ & $0.76(d, 6.4)$ & - & - & - & - \\
\hline 31 & 18.6, $\mathrm{CH}_{3}$ & $0.52(\mathrm{~d}, 7.0)$ & - & - & - & - \\
\hline 8-OMe & - & - & $51.7, \mathrm{CH}_{3}$ & 3.24 (s) & - & - \\
\hline $9-\mathrm{OH}$ & - & - & - & $6.31(\mathrm{~s})$ & - & - \\
\hline
\end{tabular}

(-4.70), $250(+5.58), 278(-32.22), 314(+8.18) \mathrm{nm}$; IR (KBr) $v_{\max }$ $3,370,2,958,2,929,2,850,1,723,1,703,1,627,1,449,1,263$, $1,104 \mathrm{~cm}^{-1} ;{ }^{1} \mathrm{H}$ and ${ }^{13} \mathrm{C}$ NMR data (see Table 1);HRESIMS $\mathrm{m} / \mathrm{z}$ $468.1623[\mathrm{M}+\mathrm{Na}]^{+}$(calcd for $\mathrm{C}_{23} \mathrm{H}_{27} \mathrm{NNaO}_{8}, 468.1629$ ).

Tryptoquivaline $\mathrm{Z}(3)$ : White amorphous powder; $[\alpha]_{D}^{25}+135$ (c 0.10, MeOH); UV (MeOH) $\lambda_{\max }(\log \varepsilon) 208$ (4.33), 296 (3.28) $\mathrm{nm} ; \mathrm{CD}(0.11 \mathrm{mM}, \mathrm{MeOH}) \lambda_{\max }(\Delta \varepsilon) 222$ (-11.10), 244 (-2.27), 258 (-4.95), $302(+1.30) \mathrm{nm}$; IR (KBr) $v_{\max } 3,359,2,932,1712$, $1,661,1,611,1,483,1,465,1,403,1,293,1,271,1,172,1,122,1,019$, 904, 758, $701 \mathrm{~cm}^{-1} ;{ }^{1} \mathrm{H}$ and ${ }^{13} \mathrm{C}$ NMR data (see Table 1); HRESIMS $m / z$ 451.1622 $[\mathrm{M}+\mathrm{H}]^{+}$(calcd for $\mathrm{C}_{23} \mathrm{H}_{23} \mathrm{~N}_{4} \mathrm{O}_{6}$, 451.1612).

\section{Computational Details}

All the quantum mechanical calculations were performed using Gaussian 09 (Frisch et al., 2009). Systematic conformational searches were done for each compound in the gas phase using the MMFF force field, implemented in Spartan 14 (Spartan'14), and the results were validated using Macromodel (MacroModel, 2018) (MMFF force field, mixed torsional/low-mode sampling protocol) using an energy cutoff of $10 \mathrm{kcal} / \mathrm{mol}$. The choice for the $10 \mathrm{kcal} / \mathrm{mol}$ of cutoff was set as a balance between reducing the overall CPU calculation time and minimizing the possibility of losing further contributing conformers. The numbers of unique conformations found within these boundaries were 92 for $\mathbf{1}, 73$ for 11 epi-1, and 290 for $\mathbf{2}$. All conformers were kept for full geometry optimization at the RHF/3-21G level in gas phase. All structures within $5 \mathrm{kcal} / \mathrm{mol}$ from the corresponding global minima were reoptimized at the $\mathrm{B} 3 \mathrm{LYP} / 6-31 \mathrm{G}^{*}$ level in gas phase. Frequency calculations were done at the same level to determine the nature of the stationary points found. The ECD calculations were carried out using the B3LYP/6-31G* optimized geometries. The excitation energies $(\mathrm{nm})$ and rotatory strength $(R)$ in dipole velocity $\left(R_{v e l}\right)$ of the first forty singlet excitations were calculated using TDDFT implemented in Gaussian 09 at the PBE0/def2-SVP and B3LYP/6-31G* levels from all significantly populated conformers, which were averaged using Boltzmann weighting. The Boltzmann amplitudes obtained by refining the Gibbs free energies of all compounds at the SMD/M06-2X/6-31G* level using methanol as solvent. The calculated rotatory strength were simulated into the ECD curve as the sum of Gaussians with $0.3 \mathrm{eV}$ width at 

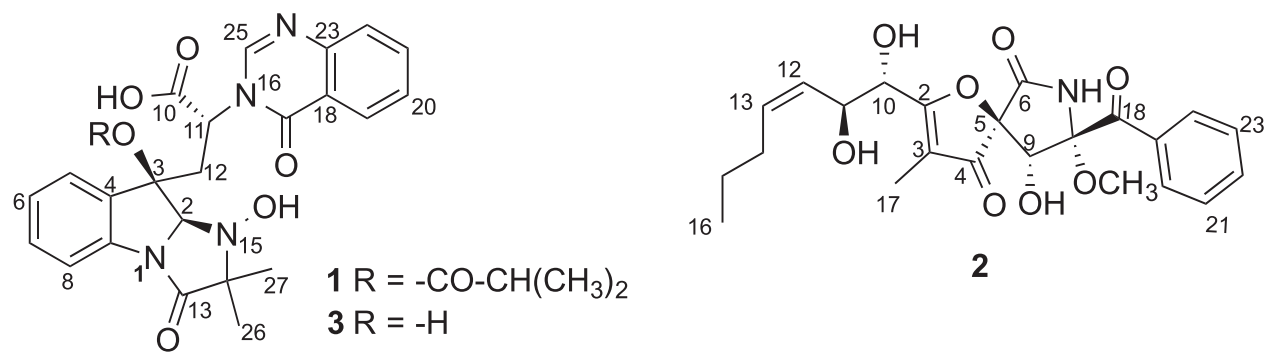

2

FIGURE 1 | Chemical structures of compounds 1-3.

half-heights $(\sigma)$, which were UV-corrected and scaled (Pescitelli and Bruhn., 2016).

\section{Antibacterial Assays}

Antibacterial assay was conducted by the previously described method (Cheng et al., 2013). DMSO (5\%) was used as negative controls whereas chloramphenicol was used as a positive control, which was active against $S$. aureus, methicillin resistant $S$. aureus, Bacillus subtilis and E. coli with MIC values ranging from $2.5 \mu \mathrm{g} /$ $\mathrm{ml}$ to $12.5 \mu \mathrm{g} / \mathrm{ml}$. The maximum concentration of the used compounds was $160 \mu \mathrm{g} / \mathrm{ml}$. All experiments were repeatedly performed in triplicate.

\section{Anti-Proliferative Assays}

The viability of A2780 human ovarian cancer cells was determined using the CyQuant assay according to the manufacturer's instructions (Life Technologies, CA, United States). Briefly, cells were cultured in 96-well plates at $5 \times 10^{3}$ cells per well for $24 \mathrm{~h}$ and subsequently treated with compounds $(50 \mu \mathrm{M})$ for $72 \mathrm{~h}$ and analyzed. Relative viability of the treated cells was normalized to the DMSO-treated control cells (Cao et al., 2007; Cao et al., 2010; Hou et al., 2008. Cisplatin was used as a positive control, which had an $\mathrm{IC}_{50}$ value of $0.36 \mu \mathrm{M}$. All experiments were performed in triplicate.

\section{NF-кB Assay}

We employed human embryonic kidney cells 293, Panomic for monitoring changes occurring along the NF- $\kappa \mathrm{B}$ pathway (Li et al., 2017). Stable constructed cells were seeded into 96-well plates at $20 \times 10^{3}$ cells per well. Cells were maintained in Dulbecco's modified Eagle's medium (DMEM) (Invitrogen Co.), supplemented with $10 \% \mathrm{FBS}, 100$ units/mL penicillin, $100 \mu \mathrm{g} /$ $\mathrm{ml}$ streptomycin, and $2 \mathrm{mM} \mathrm{L}$-glutamine. After $48 \mathrm{~h}$ incubation, the medium was replaced and the cells were treated with various concentrations of test substances. TNF- $\alpha$ (human, recombinant, E. coli, Calbiochem) was used as an activator at a concentration of $2 \mathrm{ng} / \mathrm{ml}(0.14 \mathrm{nM})$. The plate was incubated for $6 \mathrm{~h}$. Spent medium was discarded, and the cells were washed once with PBS. Cells were lysed using $50 \mu \mathrm{L}$ (for 96-well plate) of reporter lysis buffer from Promega by incubating for $5 \mathrm{~min}$ on a shaker, and stored at $-80^{\circ} \mathrm{C}$. The luciferase assay was performed using the Luc assay system from Promega. The gene product, luciferase enzyme, reacts with luciferase substrate, emitting light, which was detected using a luminometer (LUMIstar Galaxy BMG). Data for

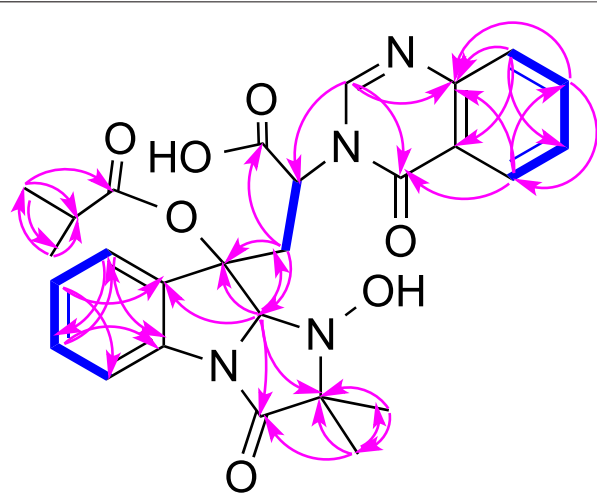

FIGURE 2 | Key COSY (bolds, blue), HMBC (arrows, pink) and ROESY (double arrows, pink) correlations of $\mathbf{1}$.

$\mathrm{NF}-\kappa \mathrm{B}$ inhibition are expressed as $\mathrm{IC}_{50}$ values (i.e., concentration required to inhibit TNF-induced NF- $\kappa \mathrm{B}$ activity by $50 \%$ ). The known NF- $\kappa$ B inhibitor TPCK was used as a positive control.

\section{RESULTS AND DISCUSSION}

\section{Identification of Compounds}

Compound 1 (Figure 1) was obtained as a white amorphous powder and its molecular formula was determined as $\mathrm{C}_{27} \mathrm{H}_{28} \mathrm{~N}_{4} \mathrm{O}_{7}$ by HRESIMS, indicating sixteen degrees of unsaturation. The ${ }^{13} \mathrm{C}$ NMR and HSQC spectra of one demonstrated the presence of nineteen carbons including four methyl $\left(4 \times \mathrm{CH}_{3}\right)$, nine $s p^{2}$ methines $(9 \times=\mathrm{CH})$, four $s p^{2}$ nonprotonated carbons $(4 \times=\mathrm{C})$, four carbonyls $(4 \times-\mathrm{CO})$, and one methylenes $\left(1 \times-\mathrm{CH}_{2}\right)$, three $s p^{3}$ methines $(3 \times-\mathrm{CH})$, one nitrogenated nonprotonated $s p^{3}$ carbon $(1 \times-\mathrm{C})$, and one oxygenated nonprotonated $s p^{3}$ carbon $(1 \times-C)$ (Table 1). The COSY spectrum of $\mathbf{1}$ indicated the presence of three spin systems including one $\mathrm{CH}-\mathrm{CH}_{2}$ and two $\mathrm{CH}=\mathrm{CH}-\mathrm{CH}=\mathrm{CH}$ (Figure 2). The HMBC spectrum of $\mathbf{1}$ showed long-range ${ }^{1} \mathrm{H}-{ }^{13} \mathrm{C}$ correlations from $\mathrm{H}-5\left(\delta_{\mathrm{H}} 7.36\right)$ to $\mathrm{C}-7\left(\delta_{\mathrm{C}} 130.0\right)$ and $\mathrm{C}-9\left(\delta_{\mathrm{C}}\right.$ 133.6), from $\mathrm{H}-6\left(\delta_{\mathrm{H}} 7.09\right)$ to $\mathrm{C}-4\left(\delta_{\mathrm{C}} 139.8\right)$ and $\mathrm{C}-8\left(\delta_{\mathrm{C}} 114.9\right)$, from $\mathrm{H}-7\left(\delta_{\mathrm{H}} 7.35\right)$ to $\mathrm{C}-5\left(\delta_{\mathrm{C}} 123.8\right)$ and $\mathrm{C}-9$, from $\mathrm{H}-27\left(\delta_{\mathrm{H}}\right.$ $1.13)$ to $\mathrm{C}-14\left(\delta_{\mathrm{C}} 69.4\right)$ and $\mathrm{C}-26\left(\delta_{\mathrm{C}} 18.2\right)$, from $\mathrm{H}-26\left(\delta_{\mathrm{H}} 1.34\right)$ to $\mathrm{C}-13\left(\delta_{\mathrm{C}} 173.1\right)$ and $\mathrm{C}-14$, and from $\mathrm{H}-2\left(\delta_{\mathrm{H}} 5.08\right)$ to $\mathrm{C}-3\left(\delta_{\mathrm{C}}\right.$ 84.1), C-4, C-13, and C-14 (Figure 2), which confirmed the 


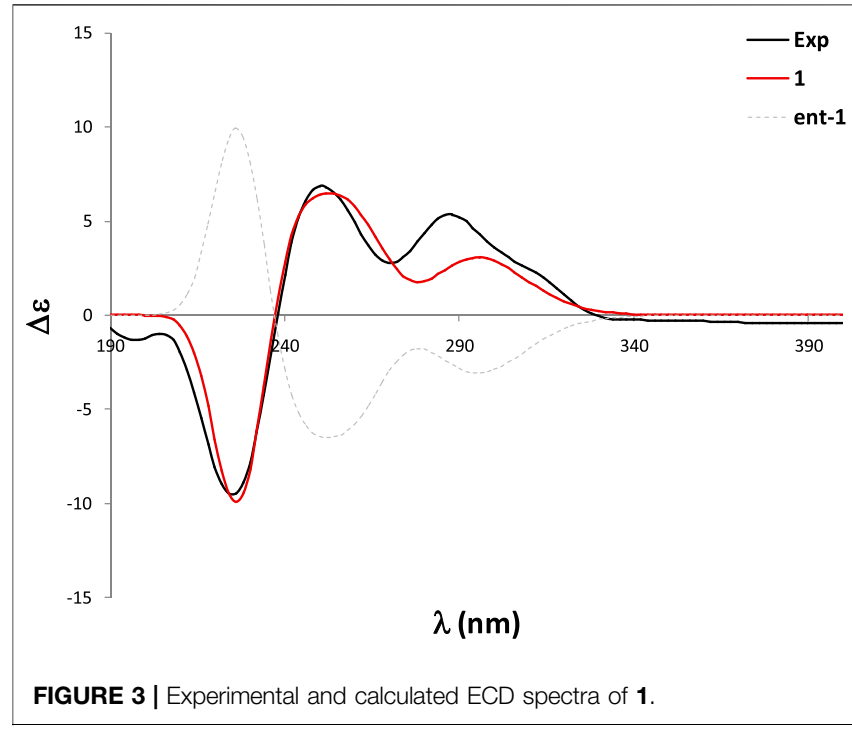

presence of an indole imidazole moiety, 2,2-dimethyl-1,2,9,9atetrahydro- $3 \mathrm{H}$-imidazo $[1,2-a]$ indol-3-one. In the $\mathrm{HMBC}$ spectrum of $1, \mathrm{H}-22\left(\delta_{\mathrm{H}} 7.75\right)$ correlated to C-20 $\left(\delta_{\mathrm{C}} 127.1\right)$ and $\mathrm{C}-18\left(\delta_{\mathrm{C}} 121.6\right), \mathrm{H}-21\left(\delta_{\mathrm{H}} 7.88\right)$ to $\mathrm{C}-19\left(\delta_{\mathrm{C}} 126.1\right)$ and $\mathrm{C}-23$ $\left(\delta_{\mathrm{C}} 147.8\right), \mathrm{H}-19\left(\delta_{\mathrm{H}} 8.19\right)$ to $\mathrm{C}-21\left(\delta_{\mathrm{C}} 134.6\right)$ and $\mathrm{C}-17\left(\delta_{\mathrm{C}} 160.2\right)$, $\mathrm{H}-25\left(\delta_{\mathrm{H}} 8.57\right)$ to $\mathrm{C}-17$ and $\mathrm{C}-23$, and $\mathrm{H}-25$ to $\mathrm{C}-17$ and $\mathrm{C}-22\left(\delta_{\mathrm{C}}\right.$ 127.1), which confirmed the presence of a quinazolin-4(3H)-one moiety. The HMBC correlations from $\mathrm{H}-12\left(\delta_{\mathrm{H}} 2.81,3.15\right)$ to $\mathrm{C}-2$ $\left(\delta_{\mathrm{C}} 85.1\right), \mathrm{C}-3$ and $\mathrm{C}-10\left(\delta_{\mathrm{C}} 170.1\right)$, and $\mathrm{H}-25$ and $\mathrm{C}-11$ indicated that the indole imidazole and quinazolin-4(3H)-one moieties were connected through the ${ }^{12} \mathrm{CH}_{2}{ }^{11} \mathrm{CH}$ spin system with a carboxylic acid group at 11-position.The HMBC spectrum of 1 also showed long-range ${ }^{1} \mathrm{H}-{ }^{13} \mathrm{C}$ correlations from $\mathrm{H}-31\left(\delta_{\mathrm{H}} 0.52\right)$ to $\mathrm{C}-29\left(\delta_{\mathrm{C}} 33.0\right)$ and C-30 $\left(\delta_{\mathrm{C}} 18.1\right), \mathrm{H}-30\left(\delta_{\mathrm{H}} 0.76\right)$ to C-28 $\left(\delta_{\mathrm{C}}\right.$ $174.0), \mathrm{C}-29$ and $\mathrm{C}-31\left(\delta_{\mathrm{C}} 18.6\right)$, indicating the presence of an isobutyric acid group in compound $\mathbf{1}$. On the basis of the NOESY correlations from $\mathrm{H}-30$ to $\mathrm{H}-25\left(\delta_{\mathrm{H}} 8.57\right)$ and $\mathrm{H}-31$ to $\mathrm{H}-5$, the isobutyric acid group must be located at 3-position (Figure 2). Finally, the hydroxyl group was assigned at 15-position because this was the only available position. Hence, the planar structure of one was determined as shown, and it was named tryptoquivaline Y. The ROESY spectrum of compound 1 exhibited correlations between $\mathrm{H}-2\left(\delta_{\mathrm{H}} 5.08\right)$ and $\mathrm{H}-12\left(\delta_{\mathrm{H}} 2.81\right)$, indicating that $\mathrm{H}-2$ and $\mathrm{H}-12$ were on the same side of the molecule.

In order to determine the absolute configuration of $\mathbf{1}$, a CD spectrum was collected, which was very similar to that of tryptovaline $\mathrm{K}$ (Zhou et al., 2012), indicating that both compounds should have the same absolute configuration. To confirm the absolute configuration of 1, TDDFT ECD calculations were carried out. The experimental ECD of $\mathbf{1}$ showed a strong negative Cotton effect (CE) at $224 \mathrm{~nm}$, and two positive CEs at 250 and $288 \mathrm{~nm}$. The MMFF conformational analysis of 1 yielded 92 conformations within the $10 \mathrm{kcal} / \mathrm{mol}$ window, which were further subsequently reoptimized at the RHF/3-21G and B3LYP/6-31G* levels. The Gibbs free energies of the most stable conformations found were further refined at

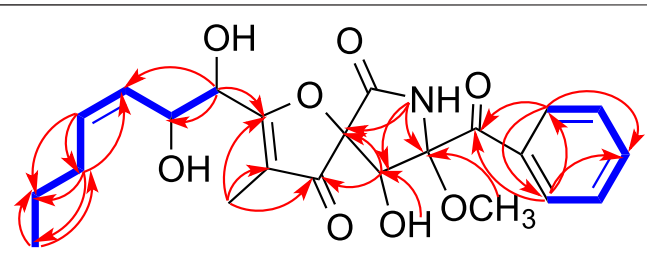

FIGURE 4 | Key COSY (bolds, blue), HMBC (arrows, red) correlations of 2.

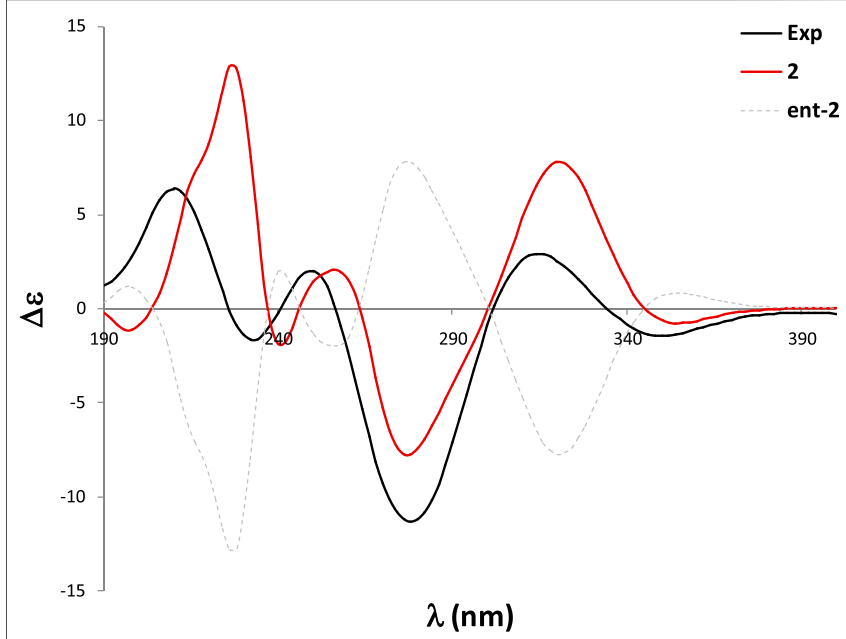

FIGURE 5 | Experimental and calculated ECD spectra of 2.

the SMD/M06-2X/6-31G* level of theory, using methanol as solvent. The ECD calculations were performed at the PBE0/ def2SVP//B3LYP/6-31G* level, and were Boltzmann-averaged using the Gibbs free energies calculated in the previous step. The same computational work was carried out with 11epi-1 in order to define the relative configuration at $\mathrm{C}-11$ as well. As shown in Figure 3, the calculated ECD of $\mathbf{1}$ showed an excellent agreement with the experimental data, allowing to assign the structure of 1 as shown. On the other hand, the calculated spectrum of 11epi-1 did not reflect good match with the experimental data (Supplementary Figures S22, 23), hence reinforcing our relative and absolute configurational assignment.

Pseurotin F (2) was obtained as white amorphous powder and has a molecular formula of $\mathrm{C}_{23} \mathrm{H}_{27} \mathrm{NO}_{8}$ derived from the HRESIMS peak at $m / z$ 468.1623 $[\mathrm{M}+\mathrm{Na}]^{+}$. The COSY spectrum of 2 exhibited the presence of two spin system, $\mathrm{CH}_{3}$ $\mathrm{CH}_{2}-\mathrm{CH}_{2}-\mathrm{CH}=\mathrm{CH}-\mathrm{CH}(\mathrm{OH})-\mathrm{CH}(\mathrm{OH})-$ and a monosubstituted benzene ring (Figure 4). HMBC correlations from $\mathrm{H}-17\left(\delta_{\mathrm{H}} 1.63\right)$ to $\mathrm{C} 2\left(\delta_{\mathrm{C}} 187.0\right)$, and $\mathrm{C}-4\left(\delta_{\mathrm{C}} 196.8\right), \mathrm{H}-9$ $\left(\delta_{\mathrm{H}} 4.40\right)$ to $\mathrm{C}-4$ and $\mathrm{C}-5\left(\delta_{\mathrm{C}} 92.5\right), 9-\mathrm{OH}\left(\delta_{\mathrm{H}} 6.31\right)$ to $\mathrm{C}-9$ $\left(\delta_{\mathrm{C}} 75.0\right), 8-\mathrm{OMe}\left(\delta_{\mathrm{H}} 3.24\right)$ to C-8 $\left(\delta_{\mathrm{C}} 91.2\right)$, and NH-7 $\left(\delta_{\mathrm{H}} 9.95\right)$ to C-5, C-8, and C-9 indicated the presence of 1-oxa-7-azaspiro [4.4]non-2-ene-4,6-dione core. An HMBC correlation from $\mathrm{H}-10$ 


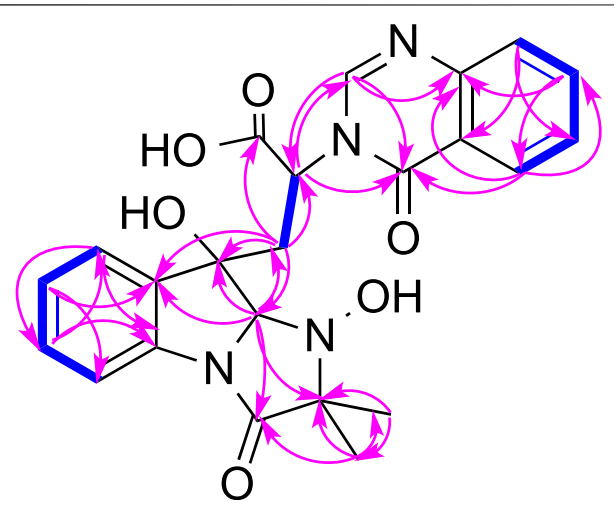

FIGURE 6 | Key COSY (bolds, blue), HMBC (arrows, pink) correlations of 3 .

$\left(\delta_{\mathrm{H}} 4.33\right)$ to $\mathrm{C}-2$ confirmed the connectivity of the spin system $\mathrm{CH}_{3}-\mathrm{CH}_{2}-\mathrm{CH}_{2}-\mathrm{CH}=\mathrm{CH}-\mathrm{CH}(\mathrm{OH})-\mathrm{CH}(\mathrm{OH})$ - to the 1-oxa-7azaspiro [4.4]non-2-ene-4,6-dione core. The mono-substituted benzene ring must be connected to the 1-oxa-7-azaspiro [4.4] non-2-ene-4,6-dione core through a ketone $(\mathrm{C}=\mathrm{O})$. Moreover, the NMR data of compound 2 (Table 1 ) were very similar to those of compound $\mathbf{8}$. The main NMR difference between $\mathbf{2}$ and $\mathbf{8}$ was attributable to one more methylene group in the chain of compound 2. No ROESY correlation between H-9 $\left(\delta_{\mathrm{H}} 4.40, \mathrm{~s}\right)$ and 8 -OMe $\left(\delta_{\mathrm{H}} 3.24, \mathrm{~s}\right)$ was observed. In fact, no other ROESY correlations were clear except for those in the two spin systems. On the other hand, the ${ }^{13} \mathrm{C}$ NMR data of compound 2 and compound $\mathbf{8}$ were almost the same, indicating both $\mathbf{2}$ and compound $\mathbf{8}$ should have the same configuration. Interestingly, compounds $\mathbf{2}$ and $\mathbf{8}$ had completely the same ECD pattern (Figure 5 and Supplementary Figure S14). Hence, it was confirmed that both compounds $\mathbf{2}$ and $\mathbf{8}$ should have the same configuration, and compound $\mathbf{2}$ was named pseurotin I.

To confirm the absolute configuration of 2 , we performed the ECD calculations. Starting with the 290 conformations found at the MMFF level, the geometries were subsequently reoptimized at the RHF/3-21G and B3LYP/6-31G* levels. The TDDFT calculations were carried at the B3LYP/6-31G* level (which in this case yielded better performance than the PBE0/def2SVP level) and were Boltzmann-averaged using the Gibbs free energies refined at the SMD/M06-2X/6-31G ${ }^{*}$ level with methanol as solvent. The calculated ECD spectrum of two was in good agreement with the experimental ECD curve, which thus allowed an unambiguous configurational assignment (Figure 5).

Tryptoquivaline $\mathrm{Z}$ (3) was obtained as white amorphous powder and has a molecular formula of $\mathrm{C}_{23} \mathrm{H}_{22} \mathrm{~N}_{4} \mathrm{O}_{6}$ derived from the HRESIMS peak at $m / z 451.1622[\mathrm{M}+\mathrm{H}]^{+}$. The NMR data of compound 3 (Table 1) were very similar to those of compound 1. The main NMR difference between $\mathbf{3}$ and $\mathbf{1}$ was that compound 1 had one extra isobutyric acid group (Figures 1, 6). Compound $\mathbf{3}$ had a similar CD spectrum to that of $\mathbf{1}$, so it was deducted that both should have the same configuration. The planar structure of compound $\mathbf{3}$ was recorded in SciFinder with an ACS registration number of 1214809-50-3 (Zheng et al., 2018), but no physio-chemical properties including NMR data were reported in the published patent (Zheng et al., 2018). The ROESY spectrum of compound 3 showed correlations between $\mathrm{H}-2\left(\delta_{\mathrm{H}} 4.88, \mathrm{~s}\right)$ and $\mathrm{H}-26\left(\delta_{\mathrm{H}} 1.30, \mathrm{~s}\right), \mathrm{H}-12\left(\delta_{\mathrm{H}} 2.74, \mathrm{~d}\right)$ (Supplementary Figures S21), which were very similar to those of compound 1. Further, compounds $\mathbf{3}$ and $\mathbf{1}$ had the similar ECD patterns, indicating that both compounds $\mathbf{3}$ and $\mathbf{1}$ should have the same configuration. Hence, the structure including the absolute configuration of compound $\mathbf{3}$ was determined as shown, and it was given a trivial name tryptoquivaline $\mathrm{Z}$.

Seven other compounds, $\beta$-cyclopiazonic acid (4) (Wang et al., 2016), cyclo-(L-Pro-L-Phe) (5) (Li et al., 2008), tryptoquivaline L (6) (Buttachon et al., 2012), Bisdethiobis (methylthio) gliotoxin (7) (Afiyatullov et al., 2005), pseurotin A (8), pseurotin $A_{1}$ (9) and pseurotin $\mathrm{A}_{2}$ (10) (Wang et al., 2011) were also isolated from Aspergillus felis FM324. The structures of these known compounds (4-10) were determined based on comparisons of NMR and HRESIMS data with previously reported data.

\section{Biological Activity}

Except for compound 4, the other nine compounds belong to three different classes of natural products, tryptoquivalines (1, 3, and 6), pseurotins (2 and 8-10) and diketopepirazines (5 and 7 ). These classes of compounds were reported to demonstrate anti-proliferative and antibacterial activities. Hence, we tested compounds 1-10 for their activities against A2780 cancer cell line, S. aureus, methicillin resistant S. aureus, Bacillus subtilis and E. coli. Besides, their anti-inflammatory activity against NF- $\kappa B$ was also evaluated. Compound $\mathbf{4}$ showed antibacterial activity against $S$. aureus, methicillin resistant $S$. aureus and Bacillus subtilis with the same MIC value of $59.2 \mu \mathrm{M}$. None of the compounds (1-10) exhibited any anti-proliferative activity against A2780, while compounds 3 and 2 inhibited NF- $\kappa B$ with $\mathrm{IC}_{50}$ values of 26.7 and $30.9 \mu \mathrm{M}$, respectively. In the absence of a cytotoxic response, inhibition of NF- $\kappa \mathrm{B}$ activity suggests the potential of cancer chemoprevention.

\section{CONCLUSION}

Aspergillus species are well known for producing tryptoquivaline and pseurotin types of compounds. Our research group previously reported two new tryptoquivaline from Aspergillus terreus (Zaman K. A. U. et al., 2020). Pseurotins, with 1-oxa-7-azaspiro [4.4]non-2-ene-4,6-dione core, were also isolated from another Aspergillus species (Wang et al., 2011). In our current research, one new tryptoquivaline (1) and one new pseurotin (2) together with eight known compounds (3-10) were isolated from a Hawaiian fungal strain Aspergillus felis FM324. The absolute configuration and physicochemical properties of compound 3 were also described for the first time. Compound 4 showed weak antibacterial activity against Gram-positive bacteria, and compounds 2 and 3 mildly inhibited NF- $\kappa$ B. 


\section{DATA AVAILABILITY STATEMENT}

The datasets presented in this study can be found in online repositories. The names of the repository/repositories and accession number(s) can be found below: GenBank under the accession no. MZ227547.

\section{AUTHOR CONTRIBUTIONS}

CW conducted the chemical experiments, and prepared the manuscript. KAUZ did the antibacterial assay. XW performed the antiproliferative and NF- $\kappa$ B assays. AMS carried out the ECD calculations. SC initiated the project, oversaw the research, and revised the manuscript. All authors approved the submission of the manuscript for publication.

\section{FUNDING}

This research was supported by Specific research project of Guangxi for research bases and talents (AD20297036), Guangxi Natural Science Foundation under Grant

\section{REFERENCES}

Afiyatullov, S. S., Kalinovskii, A. I., Pivkin, M. V., Dmitrenok, P. S., and Kuznetsova, T. A. (2005). Alkaloids from the marine Isolate of the Fungus Aspergillus fumigatus. Chem. Nat. Compd. 41, 236-238. doi:10.1007/s10600005-0122-y

Buttachon, S., Chandrapatya, A., Manoch, L., Silva, A., Gales, L., Bruyère, C., et al. (2012). Sartorymensin, a New Indole Alkaloid, and New Analogues of Tryptoquivaline and Fiscalins Produced by Neosartorya Siamensis (KUFC 6349). Tetrahedron 68, 3253-3262. doi:10.1016/j.tet.2012.02.024

Cao, S., Brodie, P. J., Callmander, M., Randrianaivo, R., Rakotobe, E., Rasamison, V. E., et al. (2010). Saponins and a Lignan Derivative of Terminalia Tropophylla from the Madagascar Dry Forest. Phytochemistry 71, 95-99. doi:10.1016/ j.phytochem.2009.09.027

Cao, S., Norris, A., Wisse, J. H., Miller, J. S., Evans, R., and Kingston, D. G. I. (2007). Ipomoeassin F, a New Cytotoxic Macrocyclic Glycoresin from the Leaves of Ipomoea squamosafrom the Suriname Rainforest. Nat. Product. Res. 21, 872-876. doi:10.1080/14786410600929576

Cheng, B., Cao, S., Vasquez, V., Annamalai, T., Tamayo-Castillo, G., Clardy, J., et al. (2013). Identification of Anziaic Acid, a Lichen Depside from Hypotrachyna sp., as a New Topoisomerase Poison Inhibitor. PLoS One 8, e60770, 2013 . e60770. doi:10.1371/journal.pone.0060770

Deshmukh, S. K., Prakash, V., and Ranjan, N. (2017). Marine Fungi: a Source of Potential Anticancer Compounds. Front. Microbiol. 8, 2536. doi:10.3389/ fmicb.2017.02536

Elkhayat, E. S., Ibrahim, S. R. M., Mohamed, G. A., and Ross, S. A. (2016). Terrenolide S, a New Antileishmanial Butenolide from the Endophytic fungus Aspergillus terreus. Nat. Product. Res. 30, 814-820. doi:10.1080/ 14786419.2015.1072711

Fei-Zhang, D. J., Li, C., and Cao, S. (2016). Hawaii Natural Compounds Are Promising to Reduce Ovarian Cancer Deaths. Cancer Biol. Ther. 17, 709-712. doi:10.1080/15384047.2016.1178428

Frisch, M. J., Trucks, G. W., Schlegel, H. B., Scuseria, G. E., Robb, M. A., Cheeseman, J. R., et al. (2009). Gaussian 09. Wallingford, CT: Gaussian, Inc.

Hou, Y., Cao, S., Brodie, P., Miller, J. S., Birkinshaw, C., Ratovoson, F., et al. (2008). Antiproliferative Cassane Diterpenoids of Cordyla Madagascariensis sp.
(2019GXNSFBA185002), start-up funding from University of Hawaii Cancer Center (UHCC) and Daniel K. Inouye College of Pharmacy (DKICP), Seed grants from the University of Hawaii at Hilo (UH Hilo), and Hawaii Community Foundation (15ADVC-74420, 17CON-86295, and 20CON-102163) (to SC). Funding for this work was also supported by Hawaii IDeA Network for Biomedical Research Excellence III and IV (INBRE-III and INBRE-IV) project (NIGMS Grant 5P20GM103466).

\section{ACKNOWLEDGMENTS}

We would also like to express our gratitude to Justin Reinicke for his help with HRMS, NMR, optical rotation and ECD data collection.

\section{SUPPLEMENTARY MATERIAL}

The Supplementary Material for this article can be found online at: https://www.frontiersin.org/articles/10.3389/fchem.2021.724617/ full\#supplementary-material

Madagascariensis from the Madagascar Rainforest. J. Nat. Prod. 71, 150-152. doi:10.1021/np0704371

Huang, P., Li, C., Sarotti, A. M., Turkson, J., and Cao, S. (2017). Sphaerialactonam, a $\gamma$-lactam-isochromanone from the Hawaiian Endophytic Fungus Paraphaeosphaeria Sp. FT462. Tetrahedron Lett. 58, 1330-1333. doi:10.1016/j.tetlet.2017.02.052

Ibrahim, S. R. M., and Asfour, H. Z. (2018). Bioactive $\gamma$-butyrolactones from Endophytic Fungus Aspergillus versicolor. Int. J. Pharmacol. 14, 437-443. doi:10.3923/ijp.2018.437.443

Ibrahim, S. R. M., Mohamed, G. A., and Khedr, A. I. M. (2017a). $\gamma$-Butyrolactones from Aspergillus Species: Structures, Biosynthesis, and Biological Activities. Nat. Product. Commun. 12, 791-800. doi:10.1177/1934578X1701200526

Ibrahim, S. R. M., Mohamed, G. A., and Ross, S. A. (2017b). Aspernolides L and M, New Butyrolactones from the Endophytic Fungus Aspergillus versicolor. Z. Naturforsch. C. 72, 155-160. doi:10.1515/znc-2016-0138

Li, C.-S., Ding, Y., Yang, B.-J., Miklossy, G., Yin, H.-Q., Walker, L. A., et al. (2015). A New Metabolite with a Unique 4-Pyranone- $\gamma$-Lactam-1,4-Thiazine Moiety from a Hawaiian-Plant Associated Fungus. Org. Lett. 17, 3556-3559. doi:10.1021/acs.orglett.5b01650

Li, C.-S., Ren, G., Yang, B.-J., Miklossy, G., Turkson, J., Fei, P., et al. (2016). Meroterpenoids with Antiproliferative Activity from a Hawaiian-Plant Associated Fungus Peyronellaea coffeae-arabicae FT238. Org. Lett. 18, 2335-2338. doi:10.1021/acs.orglett.6b00685

Li, C.-S., Sarotti, A. M., Huang, P., Dang, U. T., Hurdle, J. G., Kondratyuk, T. P., et al. (2017). NF-kB Inhibitors, Unique $\gamma$-pyranol- $\gamma$-lactams with Sulfide and Sulfoxide Moieties from Hawaiian Plant Lycopodiella Cernua Derived Fungus Paraphaeosphaeria neglecta FT462. Sci. Rep. 7, 10424. doi:10.1038/s41598-01710537-1

Li, C., Hu, Z., Liu, Q., Wu, X., and Cao, S. (2018). Two New Tricycloalternarenes from Hawaiian Endophytic Fungus Didymella Sp. FT433. Tetrahedron Lett. 59, 3381-3383. doi:10.1016/j.tetlet.2018.07.061

Li, C., Sarotti, A. M., Wu, X., Yang, B., Turkson, J., Chen, Y., et al. (2019). An Unusual Benzoisoquinoline-9-One Derivative and Other Related Compounds with Antiproliferative Activity from Hawaiian Endophytic Fungus Peyronellaea Sp. FT431. Molecules 24, 196. doi:10.3390/molecules24010196

Li, Z., Peng, C., Shen, Y., Miao, X., Zhang, H., and Lin, H. (2008). L,L-Diketopiperazines from Alcaligenes Faecalis A72 Associated with south china Sea Sponge Stelletta Tenuis. Biochem. Syst. Ecol. 36, 230-234. doi:10.1016/j.bse.2007.08.007 
Liu, D., Coloe, S., Baird, R., and Pedersen, J. (2000). Rapid Mini-Preparation of Fungal DNA for PCR. J. Clin. Microbiol. 38, 471. doi:10.1128/JCM.38.1.471471.2000

MacroModel (2018). Schrodinger Release 2018-3. New York: Schrodinger LLC.

Mohamed, G. A., Ibrahim, S. R. M., and Asfour, H. Z. (2020). Antimicrobial Metabolites from the Endophytic Fungus Aspergillus versicolor. Phytochemistry Lett. 35, 152-155. doi:10.1016/j.phytol.2019.12.003

Overy, D., Rämä, T., Oosterhuis, R., Walker, A., and Pang, K.-L. (2019). The Neglected Marine Fungi, Sensu Stricto, and Their Isolation for Natural Products' Discovery. Mar. Drugs 17, 42. doi:10.3390/md17010042

Pescitelli, G., and Bruhn, T. (2016). Good Computational Practice in the Assignment of Absolute Configurations by TDDFT Calculations of ECD Spectra. Chirality 28, 466-474. Spartan'14; Wavefunction: Irvine, CA. doi:10.1002/chir.22600

Vadlapudi, V., Borah, N., Yellusani, K. R., Gade, S., Reddy, P., Rajamanikyam, M., et al. (2017). Aspergillus Secondary Metabolite Database, a Resource to Understand the Secondary Metabolome of Aspergillus Genus. Sci. Rep. 7, 1-10. doi:10.1038/s41598-017-07436-w

Wang, C., Tang, S., and Cao, S. (2021). Antimicrobial Compounds from marine Fungi. Phytochem. Rev. 20, 85-117. doi:10.1007/s11101-020-09705-5

Wang, F.-Z., Li, D.-H., Zhu, T.-J., Zhang, M., and Gu, Q.-Q. (2011). Pseurotin A1 and A2, Two New 1-oxa-7-azaspiro[4.4]non-2-Ene-4,6-Diones from the Holothurian-Derived Fungus Aspergillus fumigatus WFZ-25. Can. J. Chem. 89, 72-76. doi:10.1139/V10-157

Wang, F., Hu, Z., Li, C., Wu, X., and Cao, S. (2019). Circumdatin M, a New Benzodiazepine Alkaloid with a Unique Pyrimidone-4-Pyrone Moiety from a Hawaiian marine Fungus Aspergillus sp. FM242. Tetrahedron Lett. 60, 1724-1726. doi:10.1016/j.tetlet.2019.05.061

Wang, F., Sarotti, A. M., Jiang, G., Huguet-Tapia, J. C., Zheng, S.-L., Wu, X., et al. (2020). Waikikiamides A-C: Complex Diketopiperazine Dimer and Diketopiperazine-Polyketide Hybrids from a Hawaiian Marine Fungal Strain Aspergillus sp. FM242. Org. Lett. 22, 4408-4412. doi:10.1021/ acs.orglett.0c01411

Wang, L.-N., Di, W.-J., Zhang, Z.-M., Zhao, L.-l., Zhang, T., Deng, Y.-R., et al. (2016). Small-molecule Inhibitors of the Tuberculosis Target, PhenylalanyltRNA Synthetase from Penicillium griseofulvum CPCC-400528. Cogent Chem. 2, 1181536. doi:10.1080/23312009.2016.1181536
Zaman, K. A. U., Hu, Z., Wu, X., and Cao, S. (2020a). Tryptoquivalines W and X, Two New Compounds from a Hawaiian Fungal Strain and Their Biological Activities. Tetrahedron Lett. 61, 151730. doi:10.1016/j.tetlet.2020.151730

Zaman, K. A. U., Hu, Z., Wu, X., Hou, S., Saito, J., Kondratyuk, T. P., et al. (2020b). NF- $\kappa B$ Inhibitory and Antibacterial Helvolic and Fumagillin Derivatives from Aspergillus terreus. J. Nat. Prod. 83, 730-737. doi:10.1021/acs.jnatprod.9b01190

Zaman, K. A. U., Park, J. H., DeVine, L., Hu, Z., Wu, X., Kim, H. S., et al. (2021). Secondary Metabolites from the Leather Coral-Derived Fungal Strain Xylaria Sp. FM1005 and Their Glycoprotein IIb/IIIa Inhibitory Activity. J. Nat. Prod. 84, 466-473. doi:10.1021/acs.jnatprod.0c01330

Zhao, C., Liu, H., and Zhu, W. (2016). [New Natural Products from the marinederived Aspergillus Fungi-A Review]. Wei Sheng Wu Xue Bao 56, 331-362. doi:10.13343/j.cnki.wsxb.20150478

Zheng, N., Li, M., Li, S., Zhang, Y., Li, H., and Wang, J. (2018). Screening Methods of Staphylococcus auresus Inhibitors. Beijing: Faming Zhuanlin Shenqing. CN 107904279 A 20180413.

Zhou, Y., Debbab, A., Mándi, A., Wray, V., Schulz, B., Müller, W. E. G., et al. (2012). Alkaloids from the Sponge-Associated Fungus Aspergillus sp Eur. J. Org. Chem. 2013, 894-906. doi:10.1002/ejoc.20120122

Conflict of Interest: The authors declare that the research was conducted in the absence of any commercial or financial relationships that could be construed as a potential conflict of interest.

Publisher's Note: All claims expressed in this article are solely those of the authors and do not necessarily represent those of their affiliated organizations, or those of the publisher, the editors and the reviewers. Any product that may be evaluated in this article, or claim that may be made by its manufacturer, is not guaranteed or endorsed by the publisher.

Copyright (c) 2021 Wang, Sarotti, Zaman, Wu and Cao. This is an open-access article distributed under the terms of the Creative Commons Attribution License (CC BY). The use, distribution or reproduction in other forums is permitted, provided the original author(s) and the copyright owner(s) are credited and that the original publication in this journal is cited, in accordance with accepted academic practice. No use, distribution or reproduction is permitted which does not comply with these terms. 